HIRING DISCRIMINATION AGAINST WOMEN: DISTINGUISHING TASTE BASED DISCRIMINATION FROM STATISTICAL DISCRIMINATION

Emmanuel Duguet, Loic Du PARQuet, PAscale PetiT 
ISSN 2110-5472 


\title{
Hiring discrimination against women: distinguishing taste based discrimination from statistical discrimination*
}

\author{
Emmanuel Duguet ${ }^{1,4,6}$, Loïc du Parquet ${ }^{3,5,6}$ and Pascale Petit ${ }^{2,4,6}$ \\ ${ }^{1}$ Université Paris Est Créteil \\ ${ }^{2}$ Université Paris Est Marne-la-Vallée \\ ${ }^{3}$ Université du Maine \\ ${ }^{4}$ ERUDITE (EA 437) \\ ${ }^{5}$ GAINS (EA 2167) \\ ${ }^{6}$ FR TEPP CNRS 3435
}

December 2017

\begin{abstract}
We propose a new method which allows for measuring separately taste based discrimination from statistical discriminations in the hiring process. We consider two types of statistical discriminations against women: first, when a recruiter doubts the productivity of the workers; second, when a recruiter anticipates a maternity leave. We show that the experimental data that we have collected can be represented by an over-identified model, which can be estimated optimally by the Asymptotic Least Squares. The method is applied to experimental data on three construction jobs: masonry, plumbing and electricity. We find that each job exhibits a different discrimination type. Furthermore, the most obvious forms of discrimination may not be the most harmful.
\end{abstract}

JEL: C51, C93, J16, J24, J71 .

Keywords: Hiring discrimination, Field experiments, Gender, Asymptotic Least Squares, France .

${ }^{*}$ We thank Souleymane Mbaye for research assistance. We also thank the participants to the 6th TEPP Winter School (Aussois, 2015) and to the 13th TEPP Conference on Policy Evaluation (La Réunion, 2016). Corresponding author: Emmanuel Duguet, Université Paris Est, Mail des Mèches, 61 avenue du Général de Gaulle, 94010 Créteil Cedex, France. emmanuel.duguet@u-pec.fr 


\section{Introduction}

Over the last decades, women have increased their qualification level and their activity rates (OECD, 2012). However, the strong inequalities between women and men in the labour market remain a major societal challenge (Bertrand, 2010). Inequality persists in terms of working time, working conditions, occupation and sector. This leads to income inequality.

Women employment suffers both from a vertical segregation, the glass ceiling, and from a horizontal segregation, gendered occupations. Therefore, despite of the development of new technologies, women and men continue to specialize in different occupations in the USA (Hegewisch et al., 2010) and in Europe (Bettio and Verashchagina, 2009). For instance, according to OECD (2012), more than $70 \%$ of the workers in education, health and social services are women. This is of consequence in France, since the half of the gender hourly wage gap, estimated at $18.4 \%$, can be explained by occupation differences (Chamki, 2015).

Notwithstanding some progress in occupation balancing, only $17 \%$ of occupations in the French labour market included at least $40 \%$ of women or men (Naves and Wisnia-Weill, 2014). These occupations represented 16\% of French employment over 2009-2011. One of the sector were women are especially at a disadvantage is construction. In 2014, they represented $5 \%$ of this sector's total employment, even though the environment was favourable. Indeed, the Construction Federation had announced its will to triple women employment, counting on a change in mentalities, strong needs of qualified personnel and less physically demanding working conditions. At the same time, communication campaigns by public authorities are accompanying this decision by the Construction Federation. The goal of these private and public actions is to correct the over-representation of men in the construction sector. It originates both from demand and supply factors.

On the supply side, the disequilibrium could come from the under-representation of women in the construction training fields. Since few women choose the construction training channels, few candidate and get the jobs. And girls indeed do different choices than boys. According to the French Ministry of Education (2012), girls represented 1\% of the pupils or apprentices in the building-construction-roofing trainings in 2010, and $9 \%$ in the building-constructionfinishing trainings. The same year, the proportion of girls in office secretary training reached $92 \%$, and $91 \%$ in health and social occupations. On the demand side, a low proportion of women could come from hiring discrimination (Heckman, 1998). Several discrimination mechanisms may be at work. First, taste discrimination from employers, the other workers or customers may reduce the access of women to some occupations (Becker, 1957). The second mechanism, statistical discrimination, is based on beliefs about the discriminated group (Arrow, 1972; Phelps, 1972; Spence, 1973). At the hiring stage, an employer may not observe the productivity of the candidate perfectly well and, for this reason, forms an anticipation from both objective and subjective elements. At the hiring stage, women may be discriminated because of an increased risk of career interruption (maternity leaves) and, in the construction sector, because of the beliefs of the employer regarding the productivity of women in this field.

In this paper, we focus on labour demand. We examine whether there is a gender discrimination in three occupations of the construction sector. We consider three types of discriminations: taste discrimination, statistical discrimination on productivity beliefs and statistical discrimination on career interruptions. We have performed correspondence tests designed to address this issue (Firth, 1982; Neumark et al., 1996; Riach and Rich, 2002). In order to distinguish the three discrimination types, we use the differences between them. Taste discrimination should apply to all the women. Statistical discrimination on productivity beliefs should 
apply to women with standard qualifications only. The most difficult case is that of statistical discrimination on career interruptions. We can obviously not cancel the ability of young women to have children by modifying a CV template. Still, we can select offers for which there is no extra cost associated with a maternity leave. In France, the only cost for the firm is the replacement cost since the replacement revenues are paid by the Sécurité Sociale. Therefore, there should be no gender discrimination on the shortest contracts, since the replacement issue is the same for women and men.

The first section presents the experiment which produces the main statistics. The second section is about the identification of the discrimination coefficients, because the different discrimination types are entangled. In the third section we present an original method for exploiting the results of correspondence tests. We conclude to the presence of different discrimination types in the last section.

\section{The experiment}

We have collected data about the construction sector in the Paris area between February and July 2015. We have replied to all the full-time jobs posts for electricians, plumbers and masons. This includes both short term and long term contracts.

Candidates. Four candidates were sent in reply to each offer: a woman and a man with the standard qualification, and a man and a woman with an excellence qualification. Table 1 indicates the identity of the candidates. All the candidates have French sounding first and last names ${ }^{1}$ are either 23 or 24 years old, childless and own a driving licence and a car ${ }^{2}$. They had a vocational training certificate (CAP) in the same profession, in 2008 or 2009 (depending on their age). They have three professional experiences in small companies, did not experience any unemployment period and are searching on the job ${ }^{3}$. They live inside the city of Paris, in districts ("arrondissements") with comparable socio-economic characteristics ${ }^{4}$ Overall, we have given to our candidates the characteristics which are the most favourable in the French labour market according to the previous applied discrimination literature, except for the three characteristics that the wish to test (gender, qualification, maternity). We did not use any photograph to avoid appearance biases (see Rich, 2017), used standard and impersonal hobbies (sport, cinema, reading, music) and have included some differencing elements in the CV layout. We have randomized the differencing elements among the candidates.

The CAP (Cerfificat d'Aptitude Profesionelle, literally "professional capacity certificate") is a vocational training certificate which grants a qualified worker/employee degree. It exists for around 200 professions. 188,386 CAP have been granted in France in 2015. We focus on three professions: electricity, plumbing and masonry. This basic diploma is often demanded by the construction firms in their posts. We indicate it as the "required" level in our statistical model.

In order to implement our methodology, we need to distinguish short and long contracts. After examining the distribution of the contracts durations, it appears that our method is applicable if we keep, on the one hand, the contracts of 6 months or less and, on the other hand,

\footnotetext{
${ }^{1}$ A foreign origin can reduce the callback rates in the French labour market, see Duguet, du Parquet, L'Horty and Petit (2015).

${ }^{2}$ Mobility can influence the callback rates, see Duguet, du Parquet, L'Horty and Petit (2017)

${ }^{3}$ Past unemployment period can interfere with the callback rates, see Duguet, Le Gall, L'Horty and Petit (2017)

${ }^{4}$ For evidence of address discrimination, see Duguet, Gray, L'Horty, du Parquet and Petit (2017).
} 
Table 1: Experiment candidates

\begin{tabular}{lccc}
\hline \hline Candidates & Plumbing & Masonry & Electricity \\
\hline Woman, Standard & Aurélie DUVAL & Juliette LEROY & Anaïs DUBOIS \\
Woman, Excellence & Pauline LEMAIRE & Laura BONNET & Elodie FOURNIER \\
Man, Standard & Thomas ROUX & Alexandre PETIT & Julien GUERRIN \\
Man, Excellence & Jonathan MOREL & Jérémy MOREAU & Anthony DURAND \\
\hline \hline \multicolumn{2}{c}{ Standard: standard vocational training diploma (CAP, "Certificat d'Aptitude Professionnelle") } \\
Excellence: "best French apprentice" (MAF) or "Worldskills competition" (OM) regional laureates
\end{tabular}

the contracts of 12 months or more (including the permanent contracts) ${ }^{5}$

Excellence qualifications (MAF and OM). The MAF ("un des Meilleurs Apprentis de France", literally "one of the best French apprentices") is a prize created in 1986 by the MOF National Society (MOF, "un des Meilleurs Ouvriers de France" means literally "one of the best French craftsmen"), in 104 professions. Its goal is to "promote among apprentices ... the taste of well done work, asserting their personality, their passion, spirit of initiative, progress in their applied competencies, obtaining the fair reward of their effort and to testify with pride about the efficiency of their training to manual professions". Depending on their profession, the candidates must either make a craft work during 5 months or pass a trial. The best apprentices obtain a medal. The contest takes place in three steps: first, at the département level ${ }^{6}$ The best apprentices get a bronze, silver or gold medal. The silver and gold medal at this level can compete at the regional level 7 . A the regional level, the best apprentices can get a gold or silver medal. Finally, the regional gold medals can compete at the national level, were gold medals only are awarded. In 2015, there were 5196 participants (in all professions). There were 3472 laureates at the departement level, 1517 at the regional level. 817 apprentices went in final, and 316 were rewarded. The national level of the competition would send too strong a signal and cause detection because the laureates are invited to a ceremony by the President of the Senate. We indicate a gold medal at the regional level, which represent $13 \%$ of the total number of candidates.

The OM ("Olympiade des Métiers" or "Worldskills Competition") is organized by the Regional Councils in partnership with the professional and training organisms in 50 professions. It is a three-stage contest. First, at the French regional level; second, at the national level where a team is made for each profession; third, the national teams are sent at the Worldskills Competition, organized every two years. In 2015, the competition took place in Sao-Paulo. There were 1000 finalists from 59 countries. About 6000 French apprentices have participated to this competition. In order to avoid detection, we cannot use the national level selection, because the team is received by the President of the French Republic. We indicate a selection at the regional level, which represent 800 candidates out of 6000 . The selection rate is therefore $13.3 \%$, close to the MAF selection level. Overall, our excellence qualifications indicate candidates if the first decile of the competitors. This achievement could be used for international comparisons because it exists in many countries.

\footnotetext{
${ }^{5}$ Therefore, we have excluded the contracts of 7 to 11 months from all the computations

${ }^{6}$ Metropolitan France is divided into 95 département.

${ }^{7}$ Metropolitan France is divided into 22 regions
} 
Experiment and protocol tests. Table 2 provides some sample statistics. We have data 133 posts for masonry, 141 for electricity and 288 for plumbing. This corresponds to the dispatch of 2248 CVs ( $4 \times 462$ posts). The global callback rates are high, at least one of the four candidates gets a callback in $29.8 \%$ of the cases for electricity, $36.1 \%$ for plumbing and $24.8 \%$ for masonry.

Table 2: Sample Statistics

\begin{tabular}{lccc}
\multicolumn{4}{l}{ The table reports the p values for all the tests. } \\
\hline \hline Profession & Electricians & Plumbers & Masons \\
\hline Short term & 72 & 108 & 70 \\
Long term & 69 & 180 & 63 \\
Total & 141 & 288 & 133 \\
Observations & 564 & 1152 & 532 \\
\hline Call-back rate & 0.298 & 0.361 & 0.248 \\
\hline Qualifications callback equality test \\
Women & 0.896 & 0.215 & 0.472 \\
Men & 0.278 & 0.149 & 0.907 \\
\hline Independence test: & \\
Sending order & 0.571 & 0.982 & 0.986 \\
\hline \hline
\end{tabular}

We need to perform two tests in order to validate our experimental protocol. First, we check that the rotation of CVs was efficient, by performing a chi-squared test of independence between the sending order of the candidates and their callback status. Second, in order to avoid detection, we cannot send two MAF or two OM candidates. We send two CAP, one MAF and one OM candidates. This raises the issue of differentiated effects of MAF and OM candidates, and we need to test this hypothesis.

The tests are reported in Table 2. We never reject the independence assumption between the sending order and the callback status at the conventional levels ( $\mathrm{p}$-value between 0.57 and 0.98). In order to test the homogeneity of the excellence characteristics, we have performed the following test. We first compute the callback rate difference between the MAF candidates and the CAP candidate on the same posts; this difference eliminates (additive) unobserved heterogeneity. We get an estimate of the MAF advantage over the standard qualification. Then, we perform the same operation for the OM candidate and get an estimate of the callback rate advantage of the OM candidate over the standard candidates on the same posts. Finally, we test the equality of these two differences, separately for each gender and profession. This is a difference-in-differences test. The results are presented in Table 2 we never reject the homogeneity effect at conventional levels of significance (p-values between 0.149 and 0.907 ). For this reason, we will regroup the OM and MAF characteristics under the "excellence" appellation in the statistical model.

The raw callback rates are reported in Table 3 . They mix all the effects of the components model and, for this reason, are hard to interpret. Overall, men tend to be called more often than woman, so that some discrimination may be at work. In electricity, men enjoy an advantage on long term contracts, but not women. Something must restrain the hiring of women on long term contracts. For masonry, women are almost always ranked behind their male counterpart. For plumbing, men are not preferred to women for the strongest qualification, but this can happen for low qualifications. Something reduces the hiring of standard qualification women. 
Table 3: Call-back rates

\begin{tabular}{lcccc} 
Proportions. & & & & \\
\hline \hline Profession & Electrician & Plumber & Mason & Reference* \\
\hline Short term contracts: & & & & \\
woman, required & 0.111 & 0.148 & 0.057 & $\operatorname{Pr}(s, w, r)$ \\
woman, excellence & 0.139 & 0.231 & 0.100 & $\operatorname{Pr}(s, w, e)$ \\
man, required & 0.167 & 0.120 & 0.143 & $\operatorname{Pr}(s, m, r)$ \\
man, excellence & 0.153 & 0.167 & 0.171 & $\operatorname{Pr}(s, m, e)$ \\
\hline Long term contracts: & & & & \\
woman, required & 0.116 & 0.161 & 0.111 & $\operatorname{Pr}(\ell, w, r)$ \\
woman, excellence & 0.145 & 0.206 & 0.063 & $\operatorname{Pr}(\ell, w, e)$ \\
man, required & 0.246 & 0.222 & 0.079 & $\operatorname{Pr}(\ell, m, r)$ \\
man, excellence & 0.261 & 0.200 & 0.159 & $\operatorname{Pr}(\ell, m, e)$ \\
\hline Global & 0.298 & 0.361 & 0.248 & \\
\hline \hline *: reference used in the components model & & &
\end{tabular}

\section{Identification and Estimation}

We wish to distinguish taste discrimination from statistical discrimination. There are two types of statistical discrimination against young women: first, the employer may question their professional skill; second, the candidate could be pregnant in a near future. Our methodology allows for estimating these two types of statistical discrimination separately $]^{8}$

The identification of these discrimination components relies on the differences between them. Taste discrimination, like sexism, should apply to all women. It is not the case of the two other discriminations. Statistical discrimination on skills may only apply to the women with the standard skills, not to the women with excellence qualifications. Here, we use two excellence markers, which indicate workers at the top of their profession. Therefore we can assume that statistical discrimination on skills apply to the standard qualification level only. There remains to isolate statistical discrimination on pregnancy. Here, it should apply to all the women, like taste discrimination, but there is one way to isolate its effects. We use information about the length of the labour contract. If the contract is very short, the probability that a maternity could affect the firm is negligible, since the firm has anticipated the end of the contract. We consider contracts whose duration is lower than 6 months, and compare them to contracts of 12 months and more. Therefore we do not suppress the maternity characteristic from the candidates, since it is impossible, but its consequences for the firm.

Notice that this method can be easily applied to all correspondence tests: adding an extra qualification to some candidates is straightforward, and the term of labour contracts is indicated in almost all job offers. In order to clarify the important identification issue, we use a component model. We also use this model in order to discuss the issues of unobserved heterogeneity and optimal estimation.

\footnotetext{
${ }^{8}$ This is the first paper where we have developed this method. Two variants of this method, which do not address the issues of the discrimination types, have been used later in Duguet, Gray, L'Horty, du Parquet, Petit (2017) and Duguet, Le Gall, L'Horty and Petit (2017).
} 


\subsection{Identification}

We model the probability of a positive answer. Since the data are experimental, we will consider a components model. There are eight probabilities since there are two types of labour contracts (less than 6 months, 12 months and more) and we send four candidates in reply to each of them. The four candidates correspond to the two genders times the two qualifications. Gender is denoted by $w$ and $m$ (woman, man) and the qualification by $r$ and $e$ (required, excellence) and the length of the labour contract by $s$ and $\ell$ (short, long). The probabilities for the short term contracts are described by the following equations:

$$
\begin{aligned}
& \operatorname{Pr}(s, m, r)=\theta_{s}+u_{s, i} \\
& \operatorname{Pr}(s, m, e)=\theta_{s}+\theta_{e}+u_{s, i} \\
& \operatorname{Pr}(s, w, r)=\theta_{s}+\delta_{T}+\delta_{Q}+u_{s, i} \\
& \operatorname{Pr}(s, w, e)=\theta_{s}+\theta_{e}+\delta_{T}+u_{s, i}
\end{aligned}
$$

where $u_{s, i}$ is the job level heterogeneity. It may be specific to each job post and is likely to be correlated with all the other components of the model. We will eliminate this component by differencing from a benchmark case. Since the model includes a constant term, $\theta_{s}$, we can assume $\mathrm{E}\left(u_{s, i}\right)=0$ without loss of generality. The parameter $\theta_{s}$ represents the job opportunities in the labour market for short term jobs, labour market tightness, since it represents the average probability of success for a man with the required qualification. By definition, this candidate should not suffer from discrimination and provides a natural benchmark. The second probability concerns the excellence candidates. The effect of excellence is denoted $\theta_{e}$, it is not a discriminatory component, and measures the potential increase in the recruitment probability caused by an excellence qualification. We expect $\theta_{e} \geq 0$. Then come the probabilities for women. By definition, they include the gender based discrimination components, denoted $\delta$. The first component, $\delta_{T}$, is the taste discrimination coefficient. Since discrimination reduces the hiring probability, we expect $\delta_{T} \leq 0$ in the presence of a Beckerian discrimination. The statistical discrimination on the labour quality also contributes to the hiring probability, and we denote it $\delta_{Q}$. By definition, it only affects women with the standard qualification, not the other women. Finally, there is no effect related to pregnancy in this first block of equations because they deal with short term contracts. For the long term labour contract we must account for statistical discrimination related to the maternity leaves (denoted $\delta_{M}$ ). We get:

$$
\begin{aligned}
& \operatorname{Pr}(\ell, m, r)=\theta_{\ell}+u_{\ell, i} \\
& \operatorname{Pr}(\ell, m, e)=\theta_{\ell}+\theta_{e}+u_{\ell, i} \\
& \operatorname{Pr}(\ell, w, r)=\theta_{\ell}+\delta_{T}+\delta_{Q}+\delta_{M}+u_{\ell, i} \\
& \operatorname{Pr}(\ell, w, e)=\theta_{\ell}+\theta_{e}+\delta_{T}+\delta_{M}+u_{\ell, i}
\end{aligned}
$$

where $\mathrm{E}\left(u_{\ell, i}\right)=0$ without loss of generality since there is a constant term $\theta_{\ell}$. Here we should be careful that the unobserved heterogeneity term $u_{\ell, i}$ can have different distributions for long run and short run contracts, so that we cannot take a direct difference between the probabilities of the long and short run contracts. One simple reason is that we provide an application in the construction sector, where the duration of a contract may be related to the duration of a construction site. We must take the differences inside each category of labour contract before to go any further. These differences eliminate the fixed effect heterogeneity.

Since we send four candidates on each offer, we can use differencing from the benchmark case: a man with the required qualification. These probabilities measure the difference of treat- 
ment from the benchmark candidate $(s, m, r)$ :

$$
\begin{aligned}
& \mathrm{D}(s, m, e)=\operatorname{Pr}(s, m, e)-\operatorname{Pr}(s, m, r)=\theta_{e} \\
& \mathrm{D}(s, w, r)=\operatorname{Pr}(s, w, r)-\operatorname{Pr}(s, m, r)=\delta_{T}+\delta_{Q} \\
& \mathrm{D}(s, w, e)=\operatorname{Pr}(s, w, e)-\operatorname{Pr}(s, m, r)=\theta_{e}+\delta_{T}
\end{aligned}
$$

Women with the required qualifications can be discriminated both because they are woman $\left(\delta_{T}\right)$ or because the recruiter doubts their qualification $\left(\delta_{Q}\right)$. Women with an excellence qualification can be discriminated only because they are woman $\left(\delta_{T}\right)$. Using the terminology of asymptotic least squares (henceforth ALS), it is clearly possible to invert the previous system and write the parameters of interest $\left(\theta_{e}, \delta_{T}, \delta_{Q}\right)$ as functions of the auxiliary parameters (the three probability differences). We get:

$$
\begin{aligned}
\theta_{e} & =\mathrm{D}(s, m, e) \\
\delta_{T} & =\mathrm{D}(s, w, e)-\mathrm{D}(s, m, e) \\
\delta_{Q} & =\mathrm{D}(s, w, r)-(D(s, w, e)-D(s, m, e))
\end{aligned}
$$

the excellence qualification effect is measured by comparing the two male candidates, since their probabilities are not affected by discrimination; taste discrimination is measured by comparing the two excellence candidates, since statistical discrimination is absent from both probabilities, and statistical discrimination on skills is obtained by a difference in differences, equal to $\operatorname{Pr}(s, w, r)-\operatorname{Pr}(s, m, r)-(\operatorname{Pr}(s, w, e)-\operatorname{Pr}(s, m, e))$ after simplification, which represents the variation of the difference of treatment caused by excellence. For the long term contracts, we take the differences from the benchmark case $(\ell, m, r)$ :

$$
\begin{aligned}
& \mathrm{D}(\ell, m, e)=\operatorname{Pr}(\ell, m, e)-\operatorname{Pr}(\ell, m, r)=\theta_{e} \\
& \mathrm{D}(\ell, w, r)=\operatorname{Pr}(\ell, w, r)-\operatorname{Pr}(\ell, m, r)=\delta_{T}+\delta_{Q}+\delta_{M} \\
& \mathrm{D}(\ell, w, e)=\operatorname{Pr}(\ell, w, e)-\operatorname{Pr}(\ell, m, r)=\theta_{e}+\delta_{T}+\delta_{M}
\end{aligned}
$$

the first equation clearly indicates an overidentification case since it is a new way to estimate $\theta_{e}$. In order to get $\delta_{M}$, there are also two different ways to proceed. First, one can compare the probability differences for short and long run contracts, for the women with the required qualification. Second, we can use the equivalent quantity on the excellence qualification. This gives the following overidentification constraint:

$$
\begin{aligned}
& \delta_{M}=\mathrm{D}(\ell, w, r)-\mathrm{D}(s, w, r) \\
& \delta_{M}=\mathrm{D}(\ell, w, e)-\mathrm{D}(s, w, e)
\end{aligned}
$$

Overall, we have six probability differences, which represent the auxiliary parameters in the ALS terminology. From these probabilities, we estimate four structural parameters $\left(\theta_{e}, \delta_{T}, \delta_{Q}, \delta_{M}\right)$. The degree of overidentification equals $6-4=2$. It allows for an overidentification test and an optimal estimator. 


\subsection{Estimation}

The optimal estimation of the structural parameters is given by the Asymptotic Least Squares method 9 . The six probability differences can be rewriten:

$$
\underbrace{\left(\begin{array}{c}
\mathrm{D}(s, m, e) \\
\mathrm{D}(s, w, r) \\
\mathrm{D}(s, w, e) \\
\mathrm{D}(\ell, m, e) \\
\mathrm{D}(\ell, w, r) \\
\mathrm{D}(\ell, w, e)
\end{array}\right)}_{\pi}=\underbrace{\left(\begin{array}{llll}
1 & 0 & 0 & 0 \\
0 & 1 & 1 & 0 \\
1 & 1 & 0 & 0 \\
1 & 0 & 0 & 0 \\
0 & 1 & 1 & 1 \\
1 & 1 & 0 & 1
\end{array}\right)}_{A} \underbrace{\left(\begin{array}{c}
\theta_{e} \\
\delta_{T} \\
\delta_{Q} \\
\delta_{M}
\end{array}\right)}_{\beta}
$$

or

$$
\pi=A \beta
$$

This system simply represents the identification constraints. $\pi$ is the auxiliary parameter and is easily estimated from the data, $\beta$ is the interest parameter, and is not directly observable. In order to estimate $\beta$, we need to replace $\pi$ with an estimate $\hat{\pi}$. Let:

$$
\hat{\pi}=\pi+\omega
$$

where $\omega$ is the estimation error on the auxiliary parameter. Substituting into the identification constraints, we get an equation that can be used for estimation:

$$
\hat{\pi}=A \beta+\omega
$$

where $\hat{\pi}$ and $A$ are observable, so that a minimum distance estimation is feasible. Let $\Omega=$ $\mathrm{V}(\omega)$, its diagonal elements are the variances of the auxiliary parameters estimators, and the off diagonal term, the covariance between the estimators. They are correlated because the answers to all the candidates come from the same firms. The optimal estimator of $\beta$ is the Feasible Generalized Least Squares (FGLS) estimator:

$$
\hat{\beta}=\left(A^{\prime} \hat{\Omega}^{-1} A\right)^{-1} A^{\prime} \hat{\Omega}^{-1} \hat{\pi}
$$

with estimated covariance matrix:

$$
\mathrm{V}(\hat{\beta})=\left(A^{\prime} \hat{\Omega}^{-1} A\right)^{-1}
$$

where $\hat{\Omega}$ is a consistent estimate of $\Omega$. The overidentification statistic, denoted $S$, is simply an estimate of the norm on the identification constraints, we get:

$$
S=\hat{\omega}^{\prime} \hat{\Omega}^{-1} \hat{\omega}
$$

with $\hat{\omega}=\hat{\pi}-A \hat{\beta}$. Under the null hypothesis $\left(\mathrm{H}_{0}: \pi=A \beta\right)$, it is $\chi^{2}(2)$ distributed.

\footnotetext{
${ }^{9}$ It was originally developed by Gouriéroux, Monfort and Trognon (1985) and Chamberlain $(1982,1984)$
} 
Application. The results are presented in Table 4 . Our method proceeds with backward elimination, which has a different meaning in this context. When a coefficient equals zero, it often means that candidates can be regrouped. Therefore the number of observations available for estimation increases, and so does the precision of the estimate. We give a full account of the application for electricians. The first column of table 4 reports that the lowest Student statistics $(0.19)$ is associated to $\hat{\theta}_{e}$. Therefore, we set $\theta_{e}=0$ and we find that:

$$
\begin{aligned}
& \operatorname{Pr}(s, m, r)=\theta_{s}+u_{s, i} \\
& \operatorname{Pr}(s, m, e)=\theta_{s}+u_{s, i} \\
& \operatorname{Pr}(s, w, r)=\theta_{s}+\delta_{T}+\delta_{Q}+u_{s, i} \\
& \operatorname{Pr}(s, w, e)=\theta_{s}+\delta_{T}+u_{s, i} \\
& \operatorname{Pr}(\ell, m, r)=\theta_{\ell}+u_{\ell, i} \\
& \operatorname{Pr}(\ell, m, e)=\theta_{\ell}+u_{\ell, i} \\
& \operatorname{Pr}(\ell, w, r)=\theta_{\ell}+\delta_{T}+\delta_{Q}+\delta_{M}+u_{\ell, i} \\
& \operatorname{Pr}(\ell, w, e)=\theta_{\ell}+\delta_{T}+\delta_{M}+u_{\ell, i}
\end{aligned}
$$

In order to estimate $\theta_{s}$, we simply take the average of the corresponding probabilities, since the same number of candidates is sent on each offer. This is equivalent to take a new reference candidate. Instead of $(m, r)$, we take both $(m, r)$ and $(m, e)$ for both contract lengths. We get:

$$
\begin{aligned}
\frac{1}{2}(\operatorname{Pr}(s, m, r)+\operatorname{Pr}(s, m, e)) & =\theta_{s}+u_{s, i} \\
\operatorname{Pr}(s, w, r) & =\theta_{s}+\delta_{T}+\delta_{Q}+u_{s, i} \\
\operatorname{Pr}(s, w, e) & =\theta_{s}+\delta_{T}+u_{s, i} \\
\frac{1}{2}(\operatorname{Pr}(\ell, m, r)+\operatorname{Pr}(\ell, m, e)) & =\theta_{\ell}+u_{\ell, i} \\
\operatorname{Pr}(\ell, w, r) & =\theta_{\ell}+\delta_{T}+\delta_{Q}+\delta_{M}+u_{\ell, i} \\
\operatorname{Pr}(\ell, w, e) & =\theta_{\ell}+\delta_{T}+\delta_{M}+u_{\ell, i}
\end{aligned}
$$

which is the estimation basis of column (2) in table 4 . Since the Student statistic of $\hat{\delta}_{T}$ is 0.62 , wet set $\delta_{T}=0$ in the previous system and get:

$$
\begin{aligned}
\frac{1}{2}(\operatorname{Pr}(s, m, r)+\operatorname{Pr}(s, m, e)) & =\theta_{s}+u_{s, i} \\
\operatorname{Pr}(s, w, r) & =\theta_{s}+\delta_{Q}+u_{s, i} \\
\operatorname{Pr}(s, w, e) & =\theta_{s}+u_{s, i} \\
\frac{1}{2}(\operatorname{Pr}(\ell, m, r)+\operatorname{Pr}(\ell, m, e)) & =\theta_{\ell}+u_{\ell, i} \\
\operatorname{Pr}(\ell, w, r) & =\theta_{\ell}+\delta_{Q}+\delta_{M}+u_{\ell, i} \\
\operatorname{Pr}(\ell, w, e) & =\theta_{\ell}+\delta_{M}+u_{\ell, i}
\end{aligned}
$$


which leads to:

$$
\begin{aligned}
\frac{1}{3}(\operatorname{Pr}(s, m, r)+\operatorname{Pr}(s, m, e)+\operatorname{Pr}(s, w, e)) & =\theta_{s}+u_{s, i} \\
\operatorname{Pr}(s, w, r) & =\theta_{s}+\delta_{Q}+u_{s, i} \\
\frac{1}{2}(\operatorname{Pr}(\ell, m, r)+\operatorname{Pr}(\ell, m, e)) & =\theta_{\ell}+u_{\ell, i} \\
\operatorname{Pr}(\ell, w, r) & =\theta_{\ell}+\delta_{Q}+\delta_{M}+u_{\ell, i} \\
\operatorname{Pr}(\ell, w, e) & =\theta_{\ell}+\delta_{M}+u_{\ell, i}
\end{aligned}
$$

and this leads to the estimations reported in column (3) of table 4 . The Student statistics of $\hat{\delta}_{Q}$ is 1.36 and wet set $\delta_{Q}=0$ in the previous system. After some simplification we get:

$$
\begin{aligned}
\frac{1}{4}(\operatorname{Pr}(s, m, r)+\operatorname{Pr}(s, m, e)+\operatorname{Pr}(s, w, e)+\operatorname{Pr}(s, w, r)) & =\theta_{s}+u_{s, i} \\
\frac{1}{2}(\operatorname{Pr}(\ell, m, r)+\operatorname{Pr}(\ell, m, e)) & =\theta_{\ell}+u_{\ell, i} \\
\frac{1}{2}(\operatorname{Pr}(\ell, w, r)+\operatorname{Pr}(\ell, w, e)) & =\theta_{\ell}+\delta_{M}+u_{\ell, i}
\end{aligned}
$$

the first equation will be useful to estimate $\theta_{s}$ only and, therefore, will not contribute to the estimations of the discriminatory component that remains. The two other equations will be used to perform a difference and identify $\delta_{M}$. The result is reported in the fourth column of table 4 ,

\section{Results}

The three professions tested have different market tightness depending on the contract duration. Electricians are preferred on long term contracts $\left(\hat{\theta}_{\ell}=0.222>0.120=\hat{\theta}_{s}\right)$, as well as plumbers $\left(\hat{\theta}_{\ell}=0.209>0.173=\hat{\theta}_{s}\right)$ and masons on short contracts $\left(\hat{\theta}_{s}=0.157>0.119=\hat{\theta}_{\ell}\right)$. This may reflect the nature of these occupations. This is consistent with the fact that masons may be preferred for fixed term contracts because they are more often used during the construction phase, while electricians and plumbers may also be called for maintenance.

The three professions do not seem to value the excellence qualifications. This is surprising at a first glance, but it can be understood if we account for the type of jobs the posts are about. These are rather basic jobs that any worker with the right training may be able to do. In this case, the absence of an excellence effect $\left(\theta_{e}=0\right)$ would simply reflect that the recruiters do not value excellence when they do not need it. Notice that, contrary to Neumark (2012), our method does not rely on a monotonicity condition between the call-back rate and the qualification level, so that this result has no consequence for our econometric analysis. This also explains why we did not apply this method when we had planned to do so.

All the other differences between the call-back rates of the candidates come from discrimination. However, we find that the discrimination type differs from one profession to another. This justify ex post the usefulness of our estimation method. The taste based discrimination appears in the mason profession. Women have a lower call-back rate than men by $-5.8 \mathrm{pp}(\mathrm{t}-$ stat: 2.69). This results may come from preconceptions in a predominantly male activity, which relied on physical force for a long time in the past. 
Table 4: Discrimination components estimates

Estimation by the Asymptotic Least Squares method. Asymptotic Student statistics between parentheses (critical values: 1.645 at $10 \%, 1.96$ at $5 \%$ )

\begin{tabular}{|c|c|c|c|c|c|c|c|c|c|c|c|c|}
\hline \multirow{2}{*}{$\begin{array}{l}\text { Profession } \\
\text { Model }\end{array}$} & \multicolumn{4}{|c|}{ Electrician } & \multicolumn{4}{|c|}{ Plumber } & \multicolumn{4}{|c|}{ Mason } \\
\hline & (1) & (2) & (3) & (4) & (5) & (6) & (7) & (8) & (9) & (10) & (11) & (12) \\
\hline \multicolumn{13}{|l|}{ Levels } \\
\hline \multirow[t]{2}{*}{$\theta_{s}$} & 0.167 & 0.160 & 0.153 & 0.142 & 0.120 & 0.144 & 0.144 & 0.173 & 0.143 & 0.143 & 0.157 & 0.157 \\
\hline & (3.78) & (3.97) & $(4.14)$ & $(4.25)$ & (3.76) & (4.85) & (4.85) & (6.08) & (3.30) & (3.30) & (4.32) & (4.32) \\
\hline \multirow[t]{2}{*}{$\theta_{\ell}$} & 0.246 & 0.254 & 0.254 & 0.254 & 0.222 & 0.211 & 0.211 & 0.209 & 0.079 & 0.079 & 0.119 & 0.119 \\
\hline & $(4.62)$ & $(5.27)$ & $(5.27)$ & $(5.27)$ & (7.11) & $(7.80)$ & $(7.80)$ & $(8.82)$ & $(2.28)$ & $(2.28)$ & (3.55) & (3.55) \\
\hline \multicolumn{13}{|l|}{ Differences } \\
\hline \multirow{2}{*}{$\theta_{e}$} & -0.005 & & & & 0.007 & & & & 0.055 & 0.021 & & \\
\hline & $(0.19)$ & & & & $(0.35)$ & & & & (1.58) & (1.08) & & \\
\hline \multirow[t]{2}{*}{$\delta_{T}$} & -0.017 & -0.021 & & & 0.068 & 0.071 & 0.033 & & -0.107 & -0.080 & -0.081 & -0.058 \\
\hline & $(0.49)$ & $(0.62)$ & & & (1.86) & $(2.06)$ & (1.33) & & $(2.91)$ & $(2.78)$ & $(2.77)$ & (2.69) \\
\hline \multirow[t]{2}{*}{$\delta_{Q}$} & -0.036 & -0.028 & -0.036 & & -0.053 & -0.059 & -0.059 & -0.038 & 0.044 & & & \\
\hline & (1.07) & (1.04) & $(1.36)$ & & $(1.81)$ & (3.15) & (3.14) & $(2.20)$ & (1.17) & & & \\
\hline \multirow[t]{2}{*}{$\delta_{M}$} & -0.088 & -0.088 & -0.104 & -0.128 & -0.063 & -0.067 & & & 0.059 & 0.058 & 0.051 & \\
\hline & (1.52) & $(1.52)$ & (2.03) & (2.67) & (1.48) & (1.57) & & & (1.37) & (1.35) & (1.16) & \\
\hline \multirow[t]{2}{*}{$\begin{array}{l}\text { Overidentification } \\
\text { p-value }\end{array}$} & & & & & & & & & & & & \\
\hline & 0.876 & 0.982 & 0.809 & 0.443 & 0.163 & 0.315 & 0.175 & 0.509 & 0.068 & 0.080 & 0.116 & 0.130 \\
\hline
\end{tabular}

Statistical discrimination on labour qualification is found for plumbers. Women are at a disadvantage by $-3.8 \mathrm{pp}$ (t-stat: 2.20). In this case, the recruiters may trust women less than man because they believe that women would work less well.

Last but not least, we find a maternity leave discrimination for electricians. Women are at a strong disadvantage since their loss reaches $-12.8 \mathrm{pp}$ (t-stat: 2.67). In this case, the fear of career interruption by the recruiters may drive the results.

\section{Conclusion}

We find evidence of hiring discrimination against women in the construction sector. However, the discrimination types really are different from one profession to another, as well as their magnitude.

The Beckerian explanation seems to hold in masonry, where taste-based discrimination is at work. In this context all women should suffer from discrimination. Persuasive advertising campaigns could help in changing the attitudes in this field, as well as legal sanctions. The situation is different in the two other jobs that we have tested.

The occupation of electrician is characterized by a statistical discrimination on qualification. Here, the employer may doubt the competences of the female candidates. Informative advertising campaigns should give the employers the right information and contribute to reduce the discriminatory hiring gap. Increasing the internship length during the training of the apprentices may also contribute to reduce information asymmetry.

Eventually, we find that plumbing exhibits another type of discrimination. The anticipation of a maternity by the employer may hinder the chances of young women to get a job. Since the full cost of the maternity leave is incurred by the Sécurite Sociale, the issue may be about the birth-related career interruptions of women. This issue is difficult to tackle. One solution would be to increase the parental leave by men, so as to bring nearer the career interruptions of women and men. 
A last result is about the magnitude of the discrimination coefficients. We find that the stronger effect is about maternity, far above the taste based discrimination. This suggests that the most obvious forms of discrimination may not be the most harmful.

\section{References}

[1] Arrow, K. J., (1973). The Theory of Discrimination, in O. Ashenfelter and A. Rees (eds.), Discrimination in Labor Markets, Princeton, NJ: Princeton University Press.

[2] Becker, G. (1957), The Economics of Discrimination. The University of Chicago Press., 2nd ed: 1971, ISBN 0-226-04116-6.

[3] Bertrand, M. (2010). New Perspectives on Gender. Handbook of Labor Economics, Volume 4b. Elsevier, 1545-1592.

[4] Bettio, F. , Verashchagina, A. (2009). Gender Segregation in the Labour Market: Root Causes, Implications and Policy Responses in the EU. EU Expert Group on Gender and Employment (EGGE). Luxembourg: European Commission.

[5] Chamberlain, G. (1982). Multivariate regression models for panel data. Journal of Econometrics, Vol. 18 No. 1, 5-46.

[6] Chamberlain, G. (1984). Panel data. In Griliches, Z., and Intriligator, M. D. (Eds), Handbook of Econometrics, Vol. 2, North Holland, 1247-1318.

[7] Chamkhi, A. (2015). Les écarts de salaires entre femmes et hommes par zones d'emploi. Dares Analyses, No 20.

[8] Duguet E., Du Parquet L., L'Horty, Y., Petit, P. (2015). New Evidence of Ethnic and Gender discriminations in the French Labor Market using experimental data: A ranking extension of responses from correspondence tests. Annals of Economics and Statistics, No 117-118, 21-39.

[9] Duguet E., du Parquet L., L'Horty Y., Petit, P. (2017). Counterproductive hiring discrimination against women: evidence from a French correspondence test. International Journal of Manpower, forthcoming.

[10] Duguet E., Gray, D., L'Horty, Y., du Parquet, L., Petit, P. (2017). Labor market effects of urban riots: an experimental assessment. Working paper \#1711E, University of Ottawa, Department of Economics.

[11] Duguet E., Le Gall R., L'Horty Y., Petit P. (2017). How does labour market history influence the access to hiring interviews? ERUDITE Working Paper, https://ssrn.com/abstract=3037419.

[12] Firth, M. (1982). Sex Discrimination in Job Opportunities for Women. Sex Roles, 8 (8), pp. 891-901.

[13] Gouriéroux, C., Monfort, A. and Trognon, A. (1985). Moindres carrés asymptotiques. Annales de l'Insee, No. 58, 91-122. 
[14] Heckman, J. J. (1998). Detecting Discrimination. Journal of Economic Perspectives, 12(2), 101-116.

[15] Hegewisch, A., Liepmann, H., Hayes, J., Hartmann, H. (2010). Separate and not equal? Gender segregation in the labor market and the gender wage gap. Institute for Womens' Policy Research,Washington, C377.

[16] Ministry of Education, 2012. Filles et garçons, sur le chemin de l'égalité de l'école à l'enseignement supérieur.

[17] Naves, M.-C., Wisnia-Weill, V. (2014). Lutter contre les stéréotypes filles-garçons. Rapport du Commissariat Général à la stratégie et à la Prospective.

[18] Neumark, D. (2012). Detecting discrimination in audit and correspondence studies. Journal of Human Resources, 47(4), 1128-1157.

[19] Neumark D., Bank, R., Van Nort, K. (1996), Sex discrimination in restaurant hiring: an audit study. The Quaterly Journal of Economics, 111 (3), 915-941.

[20] OECD (2012). Closing the gender gap: act now. ISBN 978-92-64-17936-3, 296 p.

[21] Phelps, E. (1972). The statistical theory of racism and sexism, The American Economic Review, 62 (4), 659-661.

[22] Riach, P. A., Rich, J. (2002). Field experiments of discrimination in the market place. The economic journal, 112(483), 480-518.

[23] Spence, M. (1973). Job Market Signaling. Quarterly Journal of Economics. 87 (3): 355-374. 
Table 5: Raw data

The table give the cross-products of the call-back dummies. Each number gives the number of answers common to the two candidates indicated in line and column. The number of callbacks for each candidate is given by the diagonal of each matrix. These matrices allow for computing both $\hat{\pi}$ and $\hat{\Omega}$.

req.: required, exc.: excellence.

\begin{tabular}{|c|c|c|c|c|c|c|c|c|}
\hline & \multicolumn{8}{|c|}{ Electricians } \\
\hline & \multicolumn{4}{|c|}{ short (72) } & \multicolumn{4}{|c|}{ long (69) } \\
\hline & \multicolumn{2}{|c|}{ woman } & \multicolumn{2}{|c|}{ man } & \multicolumn{2}{|c|}{ woman } & \multicolumn{2}{|c|}{ man } \\
\hline & req. & exc. & req. & exc. & req. & exc. & req. & exc. \\
\hline woman, required & 8 & 5 & 6 & 4 & 8 & 6 & 6 & 7 \\
\hline woman,excellence & 5 & 10 & 7 & 7 & 6 & 10 & 6 & 6 \\
\hline man,required & 6 & 7 & 12 & 9 & 6 & 6 & 17 & 13 \\
\hline \multirow[t]{5}{*}{ man,excellence } & 4 & 7 & 9 & 11 & 7 & 6 & 13 & 18 \\
\hline & \multicolumn{8}{|c|}{ Plumbers } \\
\hline & \multicolumn{4}{|c|}{ short (108) } & \multicolumn{4}{|c|}{ long (180) } \\
\hline & \multicolumn{2}{|c|}{ woman } & \multicolumn{2}{|c|}{ man } & \multicolumn{2}{|c|}{ woman } & \multicolumn{2}{|c|}{ man } \\
\hline & req. & exc. & req. & exc. & req. & exc. & req. & exc. \\
\hline woman, required & 16 & 15 & 6 & 9 & 29 & 24 & 16 & 17 \\
\hline woman,excellence & 15 & 25 & 9 & 11 & 24 & 37 & 17 & 18 \\
\hline man,required & 6 & 9 & 13 & 9 & 16 & 17 & 40 & 25 \\
\hline \multirow[t]{5}{*}{ man,excellence } & 9 & 11 & 9 & 18 & 17 & 18 & 25 & 36 \\
\hline & \multicolumn{8}{|c|}{ Masons } \\
\hline & \multicolumn{4}{|c|}{ short (70) } & \multicolumn{4}{|c|}{ long(63) } \\
\hline & \multicolumn{2}{|c|}{ woman } & \multicolumn{2}{|c|}{ man } & \multicolumn{2}{|c|}{ woman } & \multicolumn{2}{|c|}{ man } \\
\hline & req. & exc. & req. & exc. & req. & exc. & req. & exc. \\
\hline woman, required & 4 & 4 & 4 & 3 & 7 & 3 & 3 & 4 \\
\hline woman,excellence & 4 & 7 & 5 & 5 & 3 & 4 & 1 & 3 \\
\hline man,required & 4 & 5 & 10 & 5 & 3 & 1 & 5 & 3 \\
\hline man,excellence & 3 & 5 & 5 & 12 & 4 & 3 & 3 & 10 \\
\hline
\end{tabular}


17-10. Pension reforms, older workers' employment and the role of job separation and finding rates in France

Sarah Le Duigou, Pierre-Jean Messe

17-9. Healthier when retiring earlier? Evidence from France

Pierre-Jean Messe, François-Charles Wolff

17-8. Revisting Hopenhayn and Nicolini's optimal unemployment insurance with job search monitoring and sanctions

Sebastien Menard, Solenne Tanguy

17-7. Ethnic Gaps in Educational Attainment and Labor-Market Outcomes: Evidence from France

Gabin Langevin, David Masclet, Fabien Moizeau, Emmanuel Peterle

17-6. Identifying preference-based discrimination in rental market: a field experiment in Paris

Mathieu Bunel, Yannick L’Horty, Loïc du Parquet, Pascale Petit

17-5. Chosen or Imposed? The location strategies of households

Emilie Arnoult, Florent Sari

17-4. Optimal income taxation with composition effects

Laurence Jacquet, Etienne Lehmann

17-3. Labor Market Effects of Urban Riots: an experimental assessment

Emmanuel Duguet, David Gray, Yannick L'Horty, Loic du Parquet, Pascale Petit

17-2. Does practicing literacy skills improve academic performance in first-year university students? Results from a randomized experiment

Estelle Bellity, Fabrices Gilles, Yannick L'Horty

17-1. Raising the take-up of social assistance benefits through a simple mailing: evidence from a French field experiment

Sylvain Chareyron, David Gray, Yannick L'Horty 
16-8. Endogenous wage rigidities, human capital accumulation and growth Ahmed Tritah

16-7. Harder, better, faster...yet stronger? Working conditions and self-declaration of chronic diseases

Eric Defebvre

16-6. The influence of mental health on job retention

Thomas Barnay, Eric Defebvre

16-5. The effects of breast cancer on individual labour market outcomes: an evaluation from an administrative panel

Thomas Barnay, Mohamed Ali Ben Halima, Emmanuel Duguet, Christine Le Clainche, Camille Regaert

16-4. Expectations, Loss Aversion, and Retirement Decisions in the Context of the 2009 Crisis in Europe

Nicolas Sirven, Thomas Barnay

16-3. How do product and labor market regulations affect aggregate employment, inequalities and job polarization? A general equilibrium approach

Julien Albertini, Jean-Olivier Hairault, François Langot, Thepthida Sopraseuth

16-2. Acces to employment with age and gender: results of a controlled experiment Laetitia Challe, Florent Fremigacci, François Langot, Yannick L'Horty, Loïc Du Parquet, Pascale Petit

16-1. An evaluation of the 1987 French Disabled Workers Act: Better paying than hiring

Thomas Barnay, Emmanuel Duguet, Christine Le Clainche, Yann Videau 
15-10. Optimal Income Taxation with Unemployment and Wage Responses: A Sufficient Statistics Approach

Kory Kroft, Kavan Kucko, Etienne Lehmann, Johannes Schmieder

15-9. Search frictions and (in) efficient vocational training over the life-cycle Arnaud Chéron, Anthony Terriau

15-8. Absenteeism and productivity: the experience rating applied to employer contributions to health insurance

Sébastien Ménard, Coralia Quintero Rojas

15-7. Take up of social assistance benefits: the case of homeless Sylvain Chareyron

15-6. Spatial mismatch through local public employment agencies. Answers from a French quasi-experiment

Mathieu Bunel, Elisabeth Tovar

15-5. Transmission of vocational skills at the end of career: horizon effect and technological or organisational change

Nathalie Greenan, Pierre-Jean Messe

15-4. Protecting biodiversity by developing bio-jobs: A multi-branch analysis with an application on French data

Jean De Beir, Céline Emond, Yannick L'Horty, Laetitia Tuffery

15-3. Profit-Sharing and Wages: An Empirical Analysis Using French Data Between 2000 and 2007

Noélie Delahaie, Richard Duhautois

15_2. A meta-regression analysis on intergenerational transmission of education: publication bias and genuine empirical effect

Nicolas Fleury, Fabrice Gilles

15_1. Why are there so many long-term unemployed in Paris?

Yannick L'Horty, Florent Sari 
14-14. Hiring discrimination based on national origin and the competition between employed and unemployed job seekers

Guillaume Pierné

14-13. Discrimination in Hiring: The curse of motorcycle women

Loïc Du Parquet, Emmanuel Duguet, Yannick L'Horty, Pascale Petit

14-12. Residential discrimination and the ethnic origin: An experimental assessment in the Paris suburbs

Emmanuel Duguet, Yannick L'Horty, Pascale Petit

14-11. Discrimination based on place of residence and access to employment Mathieu Bunel, Yannick L'Horty, Pascale Petit

14-10. Rural Electrification and Household Labor Supply: Evidence from Nigeria Claire Salmon, Jeremy Tanguy

14-9. Effects of immigration in frictional labor markets: theory and empirical evidence from EU countries

Eva Moreno-Galbis, Ahmed Tritah

14-8. Health, Work and Working Conditions: A Review of the European Economic Literature

Thomas Barnay

14-7. Labour mobility and the informal sector in Algeria: a cross-sectional comparison (2007-2012)

Philippe Adair, Youghourta Bellache

14-6. Does care to dependent elderly people living at home increase their mental health? Thomas Barnay, Sandrine Juin

14_5. The Effect of Non-Work Related Health Events on Career Outcomes: An Evaluation in the French Labor Market

Emmanuel Duguet, Christine le Clainche

14_4. Retirement intentions in the presence of technological change: Theory and evidence from France

Pierre-Jean Messe, Eva Moreno - Galbis, Francois-Charles Wolff

14_3. Why is Old Workers' Labor Market more Volatile? Unemployment Fluctuations over the Life-Cycle

Jean-Olivier Hairault, François Langot, Thepthida Sopraseuth

14_2. Participation, Recruitment Selection, and the Minimum Wage

Frédéric Gavrel

14_1. Disparities in taking sick leave between sectors of activity in France: a longitudinal analysis of administrative data

Thomas Barnay, Sandrine Juin, Renaud Legal 
13_9. An evaluation of the impact of industrial restructuring on individual human capital accumulation in France (1956-1993)

Nicolas Fleury, Fabrice Gilles

13_8. On the value of partial commitment for cooperative investment in buyer-supplier relationship

José de Sousa, Xavier Fairise

13-7. Search frictions, real wage rigidities and the optimal design of unemployment insurance

Julien Albertini, Xavier Fairise

13-6. Tax me if you can! Optimal non linear income tax between competing governments Etienne Lehmann, Laurent Simula, Alain Trannoy

13-5. Beyond the labour income tax wedge: The unemployment-reducing effect of tax progressivity

Etienne Lehmann, Claudio Lucifora, Simone Moriconi, Bruno Van Der Linden

13-4. Discrimination based on place of residence and access to employment

Mathieu Bunel, Emilia Ene Jones, Yannick L'Horty, Pascale Petit

12-3. The determinants of job access channels: evidence from the youth labor market in Franc

Jihan Ghrairi

13-2. Capital mobility, search unemployment and labor market policies: The case of minimum wages

Frédéric Gavrel

13-1. Effort and monetary incentives in Nonprofit et For-Profit Organizations Joseph Lanfranchi, Mathieu Narcy 
The CNRS Institute for Labor Studies and Public Policies (the TEPP Institute, FR n ${ }^{\circ} 3435$ CNRS) gathers together research centres specializing in economics and sociology:

- L'Equipe de Recherche sur l'Utilisation des Données Individuelles en lien avec la Théorie Economique (Research Team on Use of Individuals Data in connection with economic theory), ERUDITE, University of Paris-Est Créteil and University of ParisEst Marne-la-Vallée

- Le Centre d'Etudes des Politiques Economiques de l'université d'Evry (Research Centre focused on the analysis of economic policy and its foundations and implications), EPEE, University of Evry Val d'Essonne

- Le Centre Pierre Naville (Research on Work and Urban Policies), CPN, University of Evry Val d'Essonne

- Le Groupe d'Analyse des Itinéraires et des Niveaux Salariaux (Group on Analysis of Wage Levels and Trajectories), GAINS, University of the Maine

- Le Centre de Recherches en Economie et en Management, (Research centre in Economics and Management), CREM, University of Rennes 1 et University of Caen Basse-Normandie

- Le Groupe de Recherche ANgevin en Économie et Management (Angevin Research Group in Economics and Management), GRANEM, University of Angers ;

- Le Centre de Recherche en Economie et Droit (Research centre in Economics and Law) CRED, University of Paris II Panthéon-Assas ;

- Le Laboratoire d'Economie et de Management Nantes-Atlantique (Laboratory of Economics and Management of Nantes-Atlantique) LEMNA, University of Nantes ;

- Le Laboratoire interdisciplinaire d'étude du politique Hannah Arendt - Paris Est, LIPHA-PE

- Le Centre d'Economie et de Management de l'Océan Indien, «CEMOI», équipe d'accueil $n^{\circ} E A 13$, rattachée à l'Université de la Réunion

The TEPP Institute brings together 200 researchers and research professors and $140 \mathrm{PhD}$ students who study changes in work and employment in relation to the choices made by firms and analyse public policies using new evaluation methods. 